\title{
Association between Intracranial Atherosclerotic Calcium Burden and Angiographic Luminal Stenosis Measurements
}

\author{
(D) H. Baradaran, (DP. Patel, (D) G. Gialdini, (D)A. Giambrone, (DM.P. Lerario, (DB.B. Navi, (D).K. Min, (D) C. ladecola, (DH. Kamel, and \\ (D) A. Gupta
}

\begin{abstract}
BACKGROUND AND PURPOSE: Calcification of the intracranial vasculature is an independent risk factor for stroke. The relationship between luminal stenosis and calcium burden in the intracranial circulation is incompletely understood. We evaluated the relationship between atherosclerotic calcification and luminal stenosis in the intracranial ICAs.
\end{abstract}

MATERIALS AND METHODS: Using a prospective stroke registry, we identified patients who had both NCCT and CTA or MRA examinations as part of a diagnostic evaluation for ischemic stroke. We used NCCTs to qualitatively (modified Woodcock Visual Score) and quantitatively (Agatston-Janowitz Calcium Score) measure ICA calcium burden and used angiography to measure arterial stenosis. We calculated correlation coefficients between the degree of narrowing and calcium burden measures.

RESULTS: In 470 unique carotid arteries (235 patients), 372 (79.1\%) had atherosclerotic calcification detectable on CT compared with 160 (34\%) with measurable arterial stenosis on CTA or MRA $(P<.001)$. We found a weak linear correlation between qualitative $(R=0.48)$ and quantitative $(R=0.42)$ measures of calcium burden and the degree of luminal stenosis $(P<.001$ for both). Of 310 ICAs with $0 \%$ luminal stenosis, $216(69.7 \%)$ had measurable calcium scores.

CONCLUSIONS: There is a weak correlation between intracranial atherosclerotic calcium scores and luminal narrowing, which may be explained by the greater sensitivity of CT than angiography in detecting the presence of measurable atherosclerotic disease. Future studies are warranted to evaluate the relationship between stenosis and calcium burden in predicting stroke risk.

ABBREVIATIONS: WASID = warfarin-aspirin symptomatic intracranial disease; MWVS = Modified Woodcock Visual Score; AJ-130 = Agatston-Janowitz 130

I ntracranial atherosclerotic disease is one of the most common causes of stroke worldwide. ${ }^{1}$ Although commonly seen in Asian and African populations, intracranial atherosclerotic disease is also highly prevalent and occurs in over $80 \%$ of older, white populations as well. ${ }^{2}$ The most well-recognized biomarker to assess for future ischemic stroke risk attributable to intracranial atherosclerosis is the degree of luminal stenosis as measured on angiography. ${ }^{3,4}$ Although the composition of intracranial atherosclerotic plaque has largely

Received January 11, 2017; accepted after revision April 13.

From the Departments of Radiology (H.B., P.P., A. Gupta), Healthcare Policy and Research (A. Giambrone), and Neurology (M.P.L., B.B.N., C.I., H.K.), Clinical and Translational Neuroscience Unit, Feil Family Brain and Mind Research Institute (H.B., G.G., M.P.L., B.B.N., C.I., H.K., A. Gupta), and Dalio Institute of Cardiovascular Imaging (J.K.M.), Weill Cornell Medical College, New York, New York.

This work was supported by National Institutes of Health/National Center for Advancing Translational Sciences Grant \#KL2TR000458 to Ajay Gupta and National Institutes of Health/National Institute of Neurological Disorders and Stroke Grant \# K23NS082367 to Hooman Kamel.

Please address correspondence to Ajay Gupta, MD, 525 East 68th St, Box 141, Starr 8A, New York, NY 10065; e-mail: ajg9004@med.cornell.edu

- Indicates open access to non-subscribers at www.ajnr.org

http://dx.doi.org/10.3174/ajnr.A5310 been ignored in favor of luminal stenosis measurements, ${ }^{5}$ the Rotterdam Study, a large prospective population-based cohort, demonstrated that intracranial carotid artery wall calcification as detected on NCCT is an independent risk factor for incident stroke. ${ }^{6}$ Such data are consistent with the large body of literature showing that coronary calcium scores are a marker for the severity of coronary artery disease and a predictor of future myocardial infarction. ${ }^{7,8}$

Although both intracranial arterial stenosis and calcification are signs of atherosclerosis, the relationship between calcium burden and stenosis is incompletely understood. ${ }^{9}$ For CT calcium scoring of the intracranial ICA to be a more useful tool in stroke risk prediction, it is necessary to improve our understanding of the relationship between atherosclerotic calcification and the degree of arterial narrowing. Therefore, the purpose of this study was to evaluate the relationship between calcium burden and luminal stenosis in the intracranial ICA in patients presenting with ischemic stroke.

\section{MATERIALS AND METHODS \\ Patient Selection}

Patients with acute ischemic stroke admitted to New York Presbyterian Hospital/Weill Cornell Medical College in 2013 were 
prospectively included in the Cornell Acute Stroke Academic Registry (CAESAR). Patients were registered after an attending vascular neurologist confirmed the diagnosis of ischemic stroke. Because we were interested in comparing the degree of intracranial arterial narrowing with arterial calcification, we only included patients who had CTA or MRA examinations and NCCT with 2.5-mm section thickness examinations within 30 days of their admission for stroke. We excluded any patients with complete occlusion of their intracranial ICA and any patients in whom motion degradation precluded interpretation of their images. The institutional review board at Weill Cornell Medical College approved the collection of these data and additionally waived the need for informed consent because all medical information was already obtained for standard clinical purposes.

Trained hospital personnel collected data regarding patient demographics, the NIHSS score on admission, and vascular risk factors including tobacco use, diabetes, hypertension, dyslipidemia, atrial fibrillation, congestive heart failure, coronary heart disease, peripheral vascular disease, and cardiac valvular disease. Using the TOAST classification scheme, ${ }^{10} 2$ neurologists used all available medical records to independently assign a stroke etiology with a third neurologist independently resolving any disagreements.

\section{Imaging Technique}

We performed all head CT and CTA studies on one of the CT scanners at our institution: the Optima 660, LightSpeed Xtra, Discovery HD 750, or the LightSpeed Pro (GE Healthcare, Milwaukee, Wisconsin). We performed the CT examinations according to standard protocol for patients with suspected or known acute stroke. Head CT coverage extended from the foramen magnum to the skull vertex, with 22-cm display FOV, by using 120 $\mathrm{kVp}$ and with $\mathrm{mA}$ of 250-300, and with all images being reconstructed at $2.5-\mathrm{mm}$ axial sections. In patients who had multiple CT studies during their admission, we used the CT performed closest to the time of admission for stroke. We acquired CTA studies in helical scanning mode with coverage extending from the aortic arch to the $\mathrm{C} 1 \mathrm{ring}$. Studies were collimated at 0.625 $\mathrm{mm}$, with a $\mathrm{kvP}$ of 120 and auto-mA with a rotation time of 0.5 seconds. Approximately $90 \mathrm{~mL}$ of nonionic iodinated contrast (iohexol; Omnipaque, GE Healthcare) was administered via an 18-gauge peripheral intravenous catheter at $4-5 \mathrm{~mL} / \mathrm{s}$ by using a power injector and a SmartPrep (GE Healthcare) ROI on the aortic arch.

MRA examinations were performed on either 1.5T or 3T Signa (GE Healthcare) scanners. We performed 3D-TOF acquisitions with an FOV of $20 \mathrm{~cm}, 1.4-\mathrm{mm}$ section thickness, and a matrix of $320 \times 192$ and $320 \times 224$ on $1.5 \mathrm{~T}$ and $3 \mathrm{~T}$, respectively.

\section{Degree of Stenosis Measurements}

The degree of intracranial ICA stenosis was measured by using the warfarin-aspirin symptomatic intracranial disease (WASID) $\operatorname{method}^{11}$ with the following equation:

$$
\text { percent stenosis }=\left[1-\left(\mathrm{D}_{\text {stenosis }} / \mathrm{D}_{\text {normal }}\right)\right] \times 100
$$

where $\mathrm{D}_{\text {stenosis }}$ is the diameter of the artery at the site of the most severe degree of stenosis and $\mathrm{D}_{\text {normal }}$ is the diameter of the prox- imal normal artery at its widest, nontortuous, normal segment. To maximize the accuracy of stenosis measurements, we used a combination of MIP and axial MRA source images and multiplanar reformations and axial $0.625-\mathrm{mm}$ sections on CTA. The degree of stenosis was calculated for each ICA and categorized as $0 \%$ reflecting no detectable stenosis, $>0 \%-29 \%, 30 \%-49 \%, 50 \%-$ $69 \%$, and $70 \%-99 \%$. ICAs that were completely occluded were excluded from analysis. For intracranial ICAs without qualitative evidence of any degree of stenosis, we did not perform formal WASID measurements and considered the ICA to have $0 \%$ stenosis. To evaluate for the reproducibility of our measurements, a second radiologist independently reassessed WASID stenosis measurements on a subset of 50 intracranial ICAs.

\section{Calcium Scoring}

We measured both qualitative and semiautomated quantitative calcium scoring of each ICA separately, beginning just above its exit from the petrous temporal bone up to the level of the terminal ICA bifurcation. We excluded the petrous segment of each ICA because separating arterial wall calcification from the adjacent temporal bone was difficult. Each research imaging study was interpreted by a single radiologist who was blinded to clinical and other imaging data.

\section{Qualitative Visual Calcium Scoring}

For qualitative calcium scoring, we used the Modified Woodcock Visual Score (MWVS) scale, ${ }^{12,13}$ which uses a $0-3$ scoring scale to reflect the severity of calcification on each section of an NCCT. The scoring begins just distal to the petrous temporal bone and ends at the terminal ICA bifurcation. The scoring scale is as follows: 0 indicates no calcification; 1 reflects thin, discontinuous calcification; 2 indicates thin and continuous or thick and discontinuous calcification; and 3 reflects thick, continuous calcification. Separate scores for each right and left ICA were created by summing each axial section. For a reproducibility assessment, another radiologist independently reevaluated a subset of $50 \mathrm{MWVS}$ scores.

\section{Semiautomated Quantitative Calcium Scoring}

For quantitative calcium scoring, we used a commercially available program, Smartscore 4.0 software (GE Healthcare), to calculate Agatston-Janowitz 130 (AJ-130) Calcium Scores for each ICA. ${ }^{14}$ In the Smartscore 4.0 software, a radiologist used the manual drawing tool to circle the region containing visible calcifications within the ICA on each axial NCCT section. The software identifies calcifications with an $\mathrm{HU}$ value $>130$ and then multiplies the area by an attenuation factor (130-199 HU:1; 200-299 HU:2; 300-399 HU:3; 400+ HU:4) to calculate a calcium score for each section. A second radiologist independently drew ROIs to reassess reproducibility in a subset of $50 \mathrm{AJ}-130$ measurements.

\section{Statistical Analysis}

For comparing the proportions of patients with detectable WASID stenosis with arteries with detectable calcification, we used a McNemar test for correlated proportions. ANOVA was used to assess differences in MWVS and AJ-130 among the degree 


\begin{tabular}{|c|c|c|c|c|c|c|c|}
\hline Characteristic & $\begin{array}{l}\text { Overall (\%) } \\
(N=235)\end{array}$ & $\begin{array}{c}\text { Detectable } \\
\text { Calcification } \\
\text { in Either ICA (\%) } \\
(n=200)\end{array}$ & $\begin{array}{c}\text { No Detectable } \\
\text { Calcification } \\
\text { in Either ICA (\%) } \\
(n=35)\end{array}$ & $\begin{array}{c}P \\
\text { Value }\end{array}$ & $\begin{array}{l}\text { Detectable (>0\%) } \\
\text { Stenosis in Either } \\
\text { ICA (\%) }(n=91)\end{array}$ & $\begin{array}{l}\text { No Detectable (0\%) } \\
\text { Stenosis in Either } \\
\text { ICA }(\%)(n=144)\end{array}$ & $\begin{array}{c}P \\
\text { Value }\end{array}$ \\
\hline Age & $71.7 \pm 14.5$ & $74.9 \pm 12.1$ & $53.2 \pm 13.3$ & $<.0001$ & $76.9 \pm 10.6$ & $68.4 \pm 15.7$ & $<.0001$ \\
\hline Female & $118(50.2)$ & $100(50.0)$ & $18(51.40)$ & .88 & $45(49.5)$ & $73(50.7)$ & .85 \\
\hline Race & & & & .91 & & & .35 \\
\hline White & $210(89.4)$ & 179 (89.5) & $31(88.6)$ & & $78(85.7)$ & $132(91.7)$ & \\
\hline Black & $13(5.5)$ & $11(5.5)$ & $2(5.7)$ & & $7(7.7)$ & $6(4.2)$ & \\
\hline Other & $12(5.1)$ & $10(5.0)$ & $2(5.7)$ & & $6(6.6)$ & $6(4.2)$ & \\
\hline Atrial fibrillation & $46(19.6)$ & $44(22.0)$ & $2(5.7)$ & .02 & $20(22.0)$ & $26(18.1)$ & .46 \\
\hline Coronary artery disease & $50(21.3)$ & $47(23.5)$ & $3(8.6)$ & .05 & $26(28.6)$ & 24 (16.7) & .03 \\
\hline Carotid artery stenosis & $8(3.4)$ & $8(4.0)$ & $0(0)$ & .61 & $4(4.4)$ & $4(2.8)$ & .71 \\
\hline Diabetes mellitus & $69(29.4)$ & $64(32.0)$ & $5(14.3)$ & .03 & $38(41.8)$ & $31(21.5)$ & .001 \\
\hline Hypertension & $163(69.4)$ & 149 (74.5) & $14(40.0)$ & $<.0001$ & $77(84.6)$ & $86(59.7)$ & $<.0001$ \\
\hline Dyslipidemia & $120(51.1)$ & $113(56.5)$ & $7(20.0)$ & $<.0001$ & $57(62.6)$ & $63(43.8)$ & .01 \\
\hline NIHSS score & & & & .16 & & & .39 \\
\hline 1 & 49 (20.9) & 37 (18.5) & $12(34.3)$ & & $14(15.4)$ & $35(24.3)$ & \\
\hline 2 & $57(24.3)$ & $51(25.5)$ & $6(17.1)$ & & $22(24.2)$ & $35(24.3)$ & \\
\hline 3 & $36(15.3)$ & $30(15.0)$ & $6(17.1)$ & & $15(16.5)$ & $21(14.6)$ & \\
\hline 4 & $93(39.6)$ & $82(41.0)$ & $11(31.4)$ & & $40(44.0)$ & $53(36.8)$ & \\
\hline Prior stroke & $71(30.2)$ & $66(33.0)$ & $5(14.3)$ & .03 & $30(33.0)$ & $41(28.5)$ & .46 \\
\hline Peripheral vascular disease & $17(7.2)$ & $15(7.5)$ & $2(5.7)$ & 1.00 & $8(8.8)$ & $9(6.3)$ & .46 \\
\hline Active tobacco use & $20(8.5)$ & $16(8.0)$ & $4(11.4)$ & .51 & $8(8.8)$ & $12(8.3)$ & .90 \\
\hline IV tPA administered & $33(14.0)$ & $23(11.5)$ & $10(28.6)$ & .01 & $8(8.8)$ & $25(17.4)$ & .07 \\
\hline Valvular disease & $6(2.6)$ & $6(3.0)$ & $0(0)$ & .60 & $2(2.2)$ & $4(2.8)$ & 1.00 \\
\hline
\end{tabular}

of WASID stenosis. Pearson correlation coefficients were used to determine the linear relationship between AJ-130 and WASID stenosis, between MWVS and WASID stenosis, and between right and left arteries for MWVS, AJ-130, and WASID stenosis. Histograms were used to plot the distribution of AJ-130, MWVS, and WASID stenosis across all arteries. Interobserver agreement was assessed with a $\kappa$ coefficient and 95\% CI for MWVS and WASID stenosis and an intraclass correlation coefficient and 95\% CI for AJ-130. All $P$ values were 2 -sided and evaluated at the $.05 \alpha$ level. All analyses were performed in SAS v9.3 (SAS Institute, Cary, North Carolina).

\section{RESULTS}

\section{Patient Characteristics}

Of the 335 patients from CAESAR in 2013, we excluded 56 patients because they did not have either an MRA or CTA examination, 34 patients because they did not have a $2.5-\mathrm{mm}$ NCCT of the head, 7 patients because their intracranial ICAs were completely occluded, and 3 patients because motion degradation rendered their CT or MRA/CTA uninterpretable. Of the 235 patients included in our study, the mean age was 71.7 years (Table 1). We made WASID stenosis measurements on CTA for 84 patients and on MRA for 151 patients. Compared with patients without calcification in their intracranial ICA, patients who had detectable ICA calcification were significantly older and had a significantly higher prevalence of diabetes mellitus, hypertension, dyslipidemia, atrial fibrillation, and history of prior stroke. Patients with detectable (nonzero) stenosis of either intracranial ICA were more likely to be older and have hypertension, dyslipidemia, and coronary artery disease. Among 470 ICAs studied, 372 (79.1\%) arteries demonstrated atherosclerotic calcification detectable on NCCT, whereas $160(34 \%)$ arteries demonstrated stenosis detectable on CTA or MRA $(P<.0001)$.
There was a wide range of calcium scores and degree of WASID stenosis in our cohort, with most plaques causing $<50 \%$ luminal stenosis (Fig 1, Table 2). There were 310 intracranial ICAs with no detectable WASID stenosis ( $0 \%$ stenosis). Of these 310 ICAs without detectable intracranial stenosis, 216 (69.7\%) arteries had measurable calcium scores, which varied widely in magnitude (Fig 2). Conversely, only $4 \%$ of patients with no detectable calcium had measurable WASID stenosis (Fig 3). A total of 156/ 470 arteries (33.2\%) had neither detectable ICA stenosis nor detectable ICA calcification.

Measures of reproducibility demonstrated a $\kappa$ coefficient of 0.89 (95\% CI, $0.78-0.99$ ) for the MWVS and 0.85 (95\% CI, $0.72-$ 0.98 ) for WASID stenosis measurements. The intraclass correlation coefficient was 0.998 for the AJ-130 score (95\% CI, 0.9960.999 ), indicating outstanding interobserver reproducibility.

\section{Correlation Analyses}

There was a wide range of calcium scores in the intracranial ICAs, with a weak linear positive correlation between both quantitative and qualitative calcium scores and intracranial stenosis $(R=0.48$ and $R=0.42$, respectively; $P<.0001$ ) (Fig $4)$. We found no statistical difference in correlations of quantitative and qualitative calcium scores and intracranial stenosis when WASID stenosis was measured on CTA alone or MRA alone ( $P=.54$ and $P=.39$, respectively). There was a strong correlation between the quantitative and qualitative calcium scoring systems $(R=0.85, P<.0001)$. There was also a strong correlation between right and left intracranial ICAs for each patient's MWVSs and AJ-130 calcium scores $(R=0.91, P<$ .0001 and $R=0.90, P<.0001$, respectively) and moderate correlation between ICAs in each patient in WASID stenosis scores $(R=0.66, P<.0001)$.

AJNR Am J Neuroradiol 38:1723-29 Sep 2017 www.ajnr.org 1725 

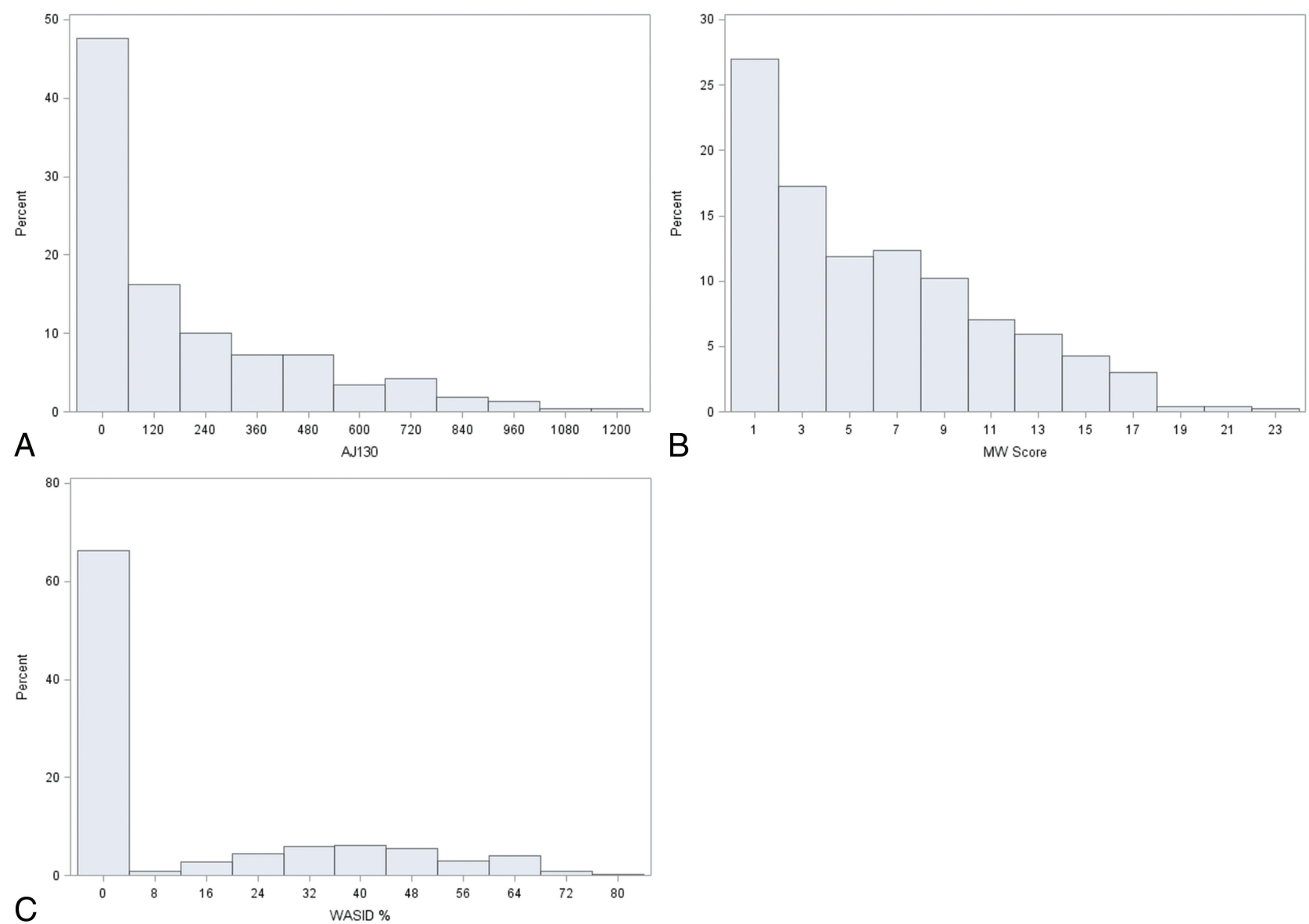

FIG 1. A, Distribution of all 470 arteries by quantitative calcium score. B, Distribution of all 470 arteries by qualitative calcium score. C, Distribution of all 470 subjects by WASID stenosis.

Table 2: Degree of intracranial WASID stenosis compared with quantitative and qualitative measures of calcium

\begin{tabular}{lccc}
\hline $\begin{array}{c}\text { Degree } \\
\text { of WASID } \\
\text { Stenosis }\end{array}$ & $\begin{array}{c}\text { Number of } \\
\text { Arteries }\end{array}$ & $\begin{array}{c}\text { MWVS } \\
\text { Mean } \pm \text { SD, } \\
\text { Median }(Q 1, Q 3)\end{array}$ & $\begin{array}{c}\text { AJ-130 Mean } \pm \text { SD, } \\
\text { Median (Q1, Q3) }\end{array}$ \\
\hline $0 \%$ & 310 & $4 \pm 4.4,2.5(0,7)$ & $114.8 \pm 194.6,23(0,144)$ \\
$>0 \%-29 \%$ & 42 & $7.8 \pm 4,7(5,11)$ & $278.8 \pm 219.1,261.5(106,411)$ \\
$30 \%-49 \%$ & 73 & $8.3 \pm 4.5,8(5,12)$ & $339.5 \pm 271.9,331(97,557)$ \\
$50 \%-69 \%$ & 41 & $9.1 \pm 5.2,8(5,15)$ & $438.7 \pm 324.6,427(155,698)$ \\
$70 \%-99 \%$ & 4 & $11.3 \pm 4.5,12.5(8,14.5)$ & $593.8 \pm 391.9,682(330.5,857)$ \\
$P$ value & & $<.0001$ & $<.0001$ \\
\hline
\end{tabular}

Note:- $Q$ indicates quartile.

\section{DISCUSSION}

In an analysis of 470 intracranial ICAs from a prospective stroke registry, we found only a weak correlation between measures of intracranial atherosclerotic calcium burden and the degree of stenosis. In addition, we found that substantially more patients had atherosclerotic calcium detected on CT compared with intracranial stenosis detected on angiography, suggesting that a routine NCCT is more sensitive in detecting the presence of any intracranial atherosclerosis than isolated CTA or MRA studies. For instance, among 310 ICAs with $0 \%$ stenosis by WASID criteria, nearly $70 \%$ had measurable atherosclerotic calcification on CT. We also found that there were strong correlations between calcium scores in right and left intracranial ICAs within each patient, but only moderate correlation in the degree of WASID stenosis between sides. Our findings of a weak correlation between the degree of intracranial stenosis and the intracranial atherosclerotic calcium burden ${ }^{15}$ and a strong correlation between qualitative and quantitative measures of intracranial atherosclerotic calcium burden are similar to the existing literature. ${ }^{16}$ Our work uniquely builds upon this knowledge by using NCCT to measure calcium burden and adapting a commonly used method for coronary calcium scoring (Agatston Score) to the intracranial ICA.

Our findings suggest that arterial calcium and degree of stenosis may provide complementary rather than overlapping data regarding atherosclerotic pathobiology and stroke risk. Histopathologic studies of the coronary arteries have shown that plaque calcification can predict overall atherosclerotic plaque burden better than the degree of arterial narrowing. ${ }^{17}$ Although NCCT is capable of detecting vessel wall calcification with high sensitivity, angiographic techniques provide detailed information about luminal caliber. The relationship between ICA calcification and stroke risk is likely multifactorial. The presence of calcified intracranial atherosclerotic disease may indicate a general state of elevated cardiovascular risk, or the calcified plaque itself may cause either flow-limiting stenosis or distal thromboembolism. ${ }^{18-21}$ The relationship between cal- 

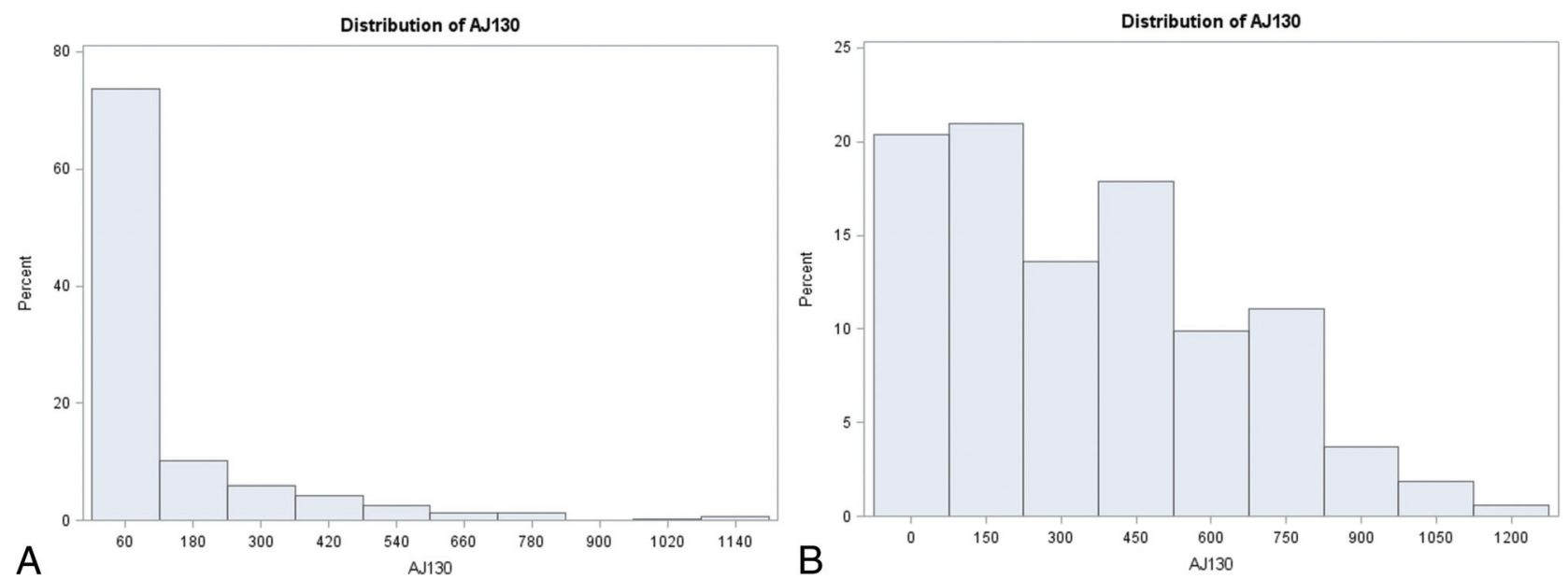

FIG 2. $A$, Distribution of AJ-130 scores in patients with no detectable $(0 \%)$ WASID stenosis. $B$, Distribution of $A J-130$ scores in patients with detectable WASID stenosis ( $>0 \%$ ).

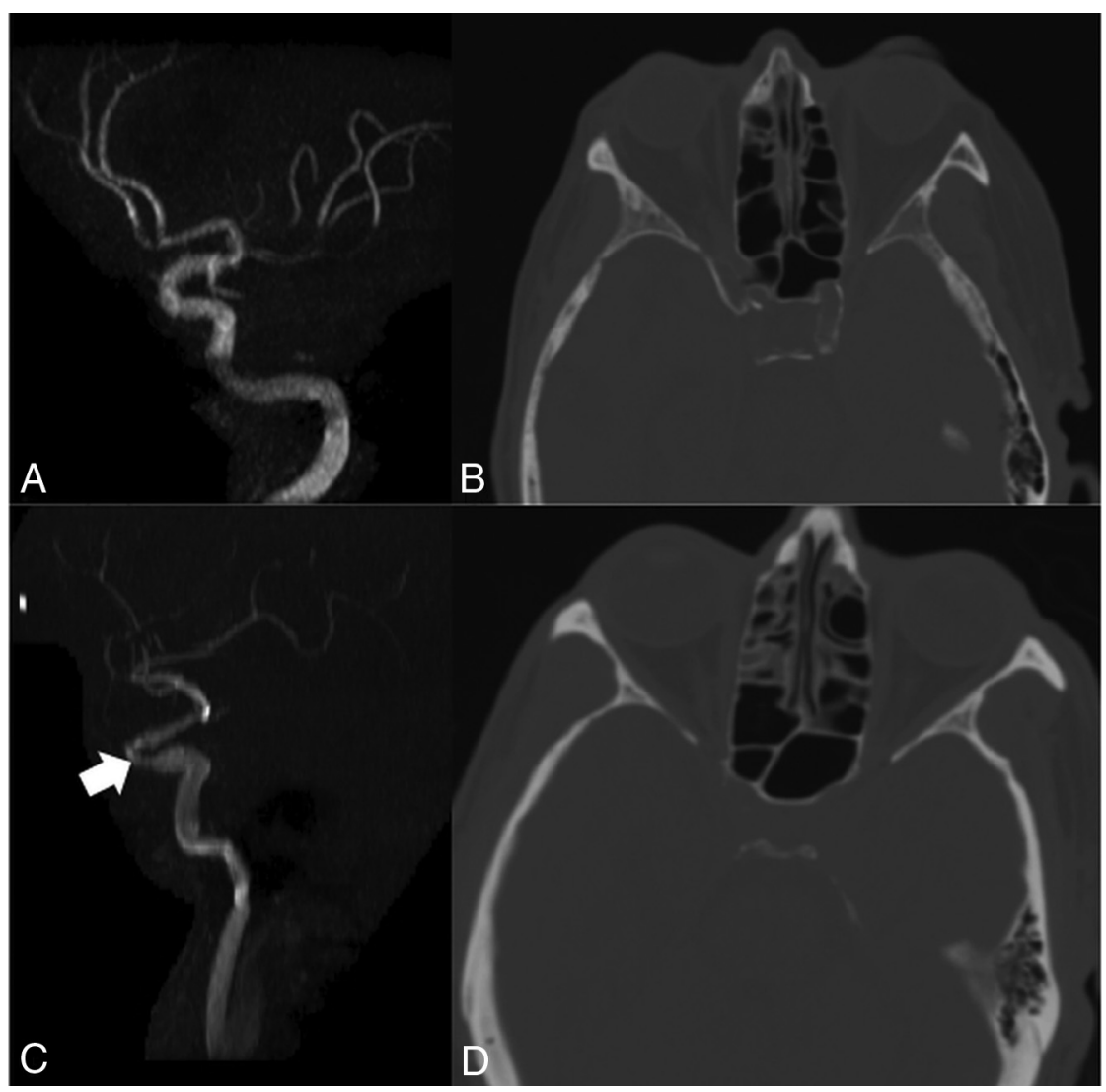

FIG 3. Imaging examples. A patient with no detectable stenosis $(A)$ of the left intracranial ICA also has NCCT showing significant calcification of the visualized intracranial left ICA (B). This patient had an AJ-130 score of 604 and an MWVS of 9. Conversely, another patient had approximately $40 \%$ stenosis of the left intracranial ICA (C, arrow) but an NCCT (D) demonstrated no calcification in the left intracranial ICA, with an AJ-130 score of 0 and an MWVS of 0.

cified intracranial vasculature and flow-limiting stenosis may also be complicated by arterial remodeling ${ }^{22,23}$ such that even with an extensive plaque burden, a vessel may not be significantly narrowed because of compensatory arterial expansion. ${ }^{24}$ Additional studies evaluating the association between nonstenosing arterial calcification and vulnerable plaque elements, such as high-resolution vessel wall MR imaging, ${ }^{25}$ may be helpful in clarifying the pathobiology of intracranial atherosclerosis.

Historically, evaluation of luminal stenosis has been the main strategy to characterize intracranial atherosclerosis for both diagnostic and treatment purposes. For example, in most stroke classification schemes, a plaque must cause $\geq 50 \%$ stenosis for a stroke to be recognized as having an atherosclerotic etiology. ${ }^{10,26}$ In addition, stroke treatment guidelines from the American Heart Association currently dictate that only patients with $\geq 50 \%$ stenosis be treated with intensive lipid-modification therapy. ${ }^{27}$ Similarly, intracranial luminal stenosis measures have been used as the imaging biomarker for patient selection into endovascular or medical treatment trials. ${ }^{5}$ Because our findings suggest that $\sim 70 \%$ of ICAs with calcification have no detectable narrowing on cross-sectional angiographic studies, many patients are likely harboring easily detectable atherosclerosis that may be ignored and, therefore, potentially undertreated. Because NCCT is nearly universally performed for patients with acute ischemic strokes, ICA calcium scoring represents a potentially useful imaging biomarker that could provide a more detailed evaluation of atherosclerotic disease burden.

Our study has several limitations. First, our study had a low proportion of patients with high-grade intracranial stenosis, likely resulting from our predominantly white population. Future studies in patient populations with a higher prevalence of intracranial stenosis, such as is found in Asian populations, may be helpful to further elucidate the relationship between severely stenotic ICAs and calcium burden. Second, whereas 

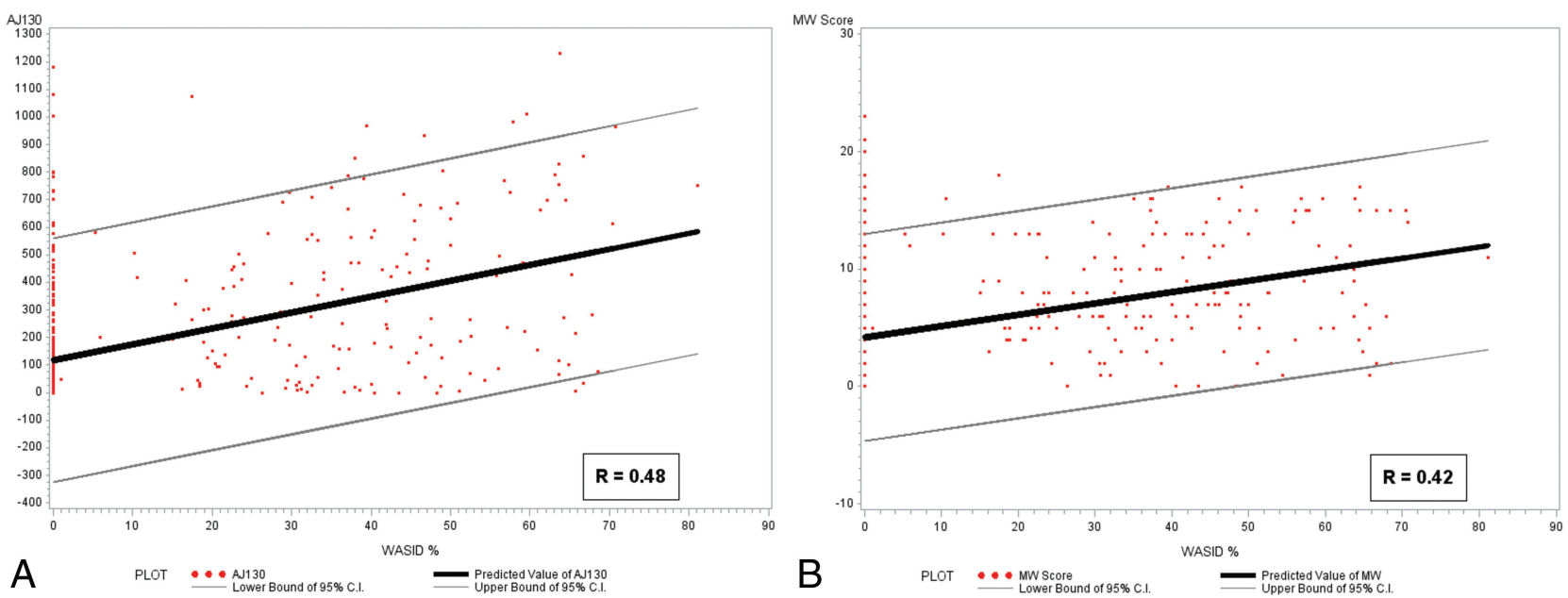

FIG 4. $A$, Correlation between quantitative (AJ-130) calcium score and WASID stenosis. B, Correlation between qualitative calcium score and WASID stenosis.

obtaining NCCT is relatively inexpensive and widely available, the manual postprocessing involved in calculating quantitative calcium scores can be modestly time-consuming, potentially adding up to 5 minutes per scan because, unlike the coronary arteries, no automated calcium scoring software currently exists for the intracranial circulation. Because our results show that the qualitative and quantitative calcium scores were similar in assessing intracranial atherosclerosis, using qualitative MWVS (requiring approximately 1 minute per case) could provide an alternative to manual quantitative calcium scoring until automated methods become more widely available. Third, our study was cross-sectional in nature, and although it provided important information regarding the relationship between intracranial stenosis and calcification, future large prospective studies are needed to evaluate the incremental utility of atherosclerotic calcium burden to predict stroke. In addition, our methods did not take into account calcification in the petrous segment of the ICA because the MWVS definition does not include the petrous segment of the ICA. The petrous segment was also excluded from analysis because evaluation of calcium burden in this segment is challenging and requires meticulous delineation of lumen from adjacent bone, a process that increases overall interpretation time and reduces the clinical utility of the technique. Last, measurements of WASID stenosis were performed on either CTA or MRA examinations, which have different sensitivities for detecting intracranial stenosis. Despite the differences in technique, we found no statistical difference in the correlation between WASID stenosis and calcium score when using CTA compared with MRA.

\section{CONCLUSIONS}

In summary, we found a relatively weak association between intracranial atherosclerotic calcification and the degree of luminal stenosis. This finding suggests that CT may be more sensitive than angiographic studies in detecting the presence of measurable atherosclerotic disease. Given that stenosis and calcium burden may be 2 largely independent features of atherosclerotic plaque, future studies are warranted to evaluate the relationship between stenosis and calcium burden in predicting stroke risk.

Disclosures: Babak Navi-RELATED: Grant: National Institutes of Health grant K23NS091395*. James K. Min—UNRELATED: Board Membership: Arineta; Grants/ Grants Pending: National Institutes of Health, GE Healthcare, Comments: Dr. Min is program director/principal or co-investigator on 5 National Institutes of Health grants and a sponsored research agreement related to cardiovascular research that is unrelated and has not funded the research discussed in this paper*; Stock/Stock Options: Heartflow, Inc., Comments: equity/ownership stock options; Other: MDDX, Comments: medical advisor and 43\% ownership. Ajay Gupta-RELATED: Grant: National Institutes of Health*. *Money paid to the institution.

\section{REFERENCES}

1. Holmstedt CA, Turan TN, Chimowitz MI. Atherosclerotic intracranial arterial stenosis: risk factors, diagnosis, and treatment. Lancet Neurol 2013;12:1106-14 CrossRef Medline

2. Bos D, van der Rijk MJ, Geeraedts TE, et al. Intracranial carotid artery atherosclerosis: prevalence and risk factors in the general population. Stroke 2012;43:1878-84 Medline

3. Gorelick PB, Wong KS, Bae HJ, et al. Large artery intracranial occlusive disease: a large worldwide burden but a relatively neglected frontier. Stroke 2008;39:2396-99 CrossRef Medline

4. Kasner SE, Chimowitz MI, Lynn MJ, et al. Predictors of ischemic stroke in the territory of a symptomatic intracranial arterial stenosis. Circulation 2006;113:555-63 CrossRef Medline

5. Derdeyn CP, Chimowitz MI, Lynn MJ, et al. Aggressive medical treatment with or without stenting in high-risk patients with intracranial artery stenosis (SAMMPRIS): the final results of a randomised trial. Lancet 2014;383:333-41 CrossRef Medline

6. Bos D, Portegies ML, van der Lugt A, et al. Intracranial carotid artery atherosclerosis and the risk of stroke in whites: the Rotterdam Study. JAMA Neurol 2014;71:405-11 CrossRef Medline

7. Shaw LJ, Giambrone AE, Blaha MJ, et al. Long-term prognosis after coronary artery calcification testing in asymptomatic patients: a cohort study. Ann Intern Med 2015;163:14-21 CrossRef Medline

8. Detrano R, Guerci AD, Carr JJ, et al. Coronary calcium as a predictor of coronary events in four racial or ethnic groups. $N$ Engl $\mathrm{J} \mathrm{Med}$ 2008;358:1336-45 CrossRef Medline

9. Chimowitz MI, Caplan LR. Is calcification of intracranial arteries important and how? JAMA Neurol 2014;71:401-02 CrossRef Medline

10. Adams HP, Bendixen BH, Kappelle LJ, et al. Classification of subtype of acute ischemic stroke. Definitions for use in a multicenter clini- 
cal trial. Toast. Trial of org 10172 in acute stroke treatment. Stroke 1993;24:35-41 CrossRef Medline

11. Samuels OB, Joseph GJ, Lynn MJ, et al. A standardized method for measuring intracranial arterial stenosis. AJNR Am J Neuroradiol 2000;21:643-46 Medline

12. Woodcock RJ Jr, Goldstein JH, Kallmes DF, et al. Angiographic correlation of CT calcification in the carotid siphon. AJNR Am J Neuroradiol 1999;20:495-99 Medline

13. Subedi D, Zishan US, Chappell F, et al. Intracranial carotid calcification on cranial computed tomography visual scoring methods, semiautomated scores, and volume measurements in patients with stroke. Stroke 2015;46:2504-09 CrossRef Medline

14. Agatston AS, Janowitz WR, Hildner FJ, et al. Quantification of coronary artery calcium using ultrafast computed tomography. J Am Coll Cardiol 1990;15:827-32 CrossRef Medline

15. Marquering HA, Nederkoorn PJ, Bleeker L, et al. Intracranial carotid artery disease in patients with recent neurological symptoms: high prevalence on CTA. Neuroradiology 2013;55:179-85 CrossRef Medline

16. Bleeker L, Marquering HA, van den Berg R, et al. Semi-automatic quantitative measurements of intracranial internal carotid artery stenosis and calcification using CT angiography. Neuroradiology 2012;54:919-27 CrossRef Medline

17. Sangiorgi G, Rumberger JA, Severson A, et al. Arterial calcification and not lumen stenosis is highly correlated with atherosclerotic plaque burden in humans: a histologic study of 723 coronary artery segments using nondecalcifying methodology. J Am Coll Cardiol 1998;31:126-33 CrossRef Medline

18. Cheung HM, Moody AR, Singh N, et al. Late stage complicated atheroma in low-grade stenotic carotid disease: MR imaging depiction-prevalence and risk factors. Radiology 2011;260: 841-47 CrossRef Medline
19. Freilinger TM, Schindler A, Schmidt C, et al. Prevalence of nonstenosing, complicated atherosclerotic plaques in cryptogenic stroke. JACC Cardiovasc Imaging 2012;5:397-405 CrossRef Medline

20. Gupta A, Gialdini G, Giambrone AE, et al. Association between nonstenosing carotid artery plaque on MR angiography and acute ischemic stroke. JACC Cardiovasc Imaging 2016;9:1228-29 CrossRef Medline

21. Gupta A, Gialdini G, Lerario MP, et al. Magnetic resonance angiography detection of abnormal carotid artery plaque in patients with cryptogenic stroke. J Am Heart Assoc 2015;4:e002012 CrossRef Medline

22. Clarkson TB, Prichard RW, Morgan TM, et al. Remodeling of coronary arteries in human and nonhuman primates. JAMA 1994;271: 289-94 CrossRef Medline

23. Qiao Y, Anwar Z, Intrapiromkul J, et al. Patterns and implications of intracranial arterial remodeling in stroke patients. Stroke 2016;47: 434-40 CrossRef Medline

24. Astor BC, Sharrett AR, Coresh J, et al. Remodeling of carotid arteries detected with MR imaging: atherosclerosis risk in communities carotid MRI study. Radiology 2010;256:879-86 CrossRef Medline

25. Mossa-Basha M, Hwang WD, De Havenon A, et al. Multicontrast high-resolution vessel wall magnetic resonance imaging and its value in differentiating intracranial vasculopathic processes. Stroke 2015;46:1567-73 CrossRef Medline

26. Amarenco P, Bogousslavsky J, Caplan L, et al. The ASCOD phenotyping of ischemic stroke (updated ASCO phenotyping). Cerebrovasc Dis 2013;36:1-5 CrossRef Medline

27. Kernan WN, Ovbiagele B, Black HR, et al. Guidelines for the prevention of stroke in patients with stroke and transient ischemic attack: a guideline for healthcare professionals from the American Heart Association/American Stroke Association. Stroke 2014;45:2160 236 CrossRef Medline 